\title{
Dynamic Patterns of Trade Imbalance and Asset- Debt Position with Adjustment Costs of Investment
}

\author{
Tadashi Inoue \\ Hosei University
}

\begin{abstract}
s
Dynamic patterns of trade imbalance and asset-debt position are analyzed employing a model of two countries, one good, two primary inputs, and identi cal technologies and preferences with investment adjustment costs. The coun tries are assumed to have different initial per capita physical capital endow ments and foreign assets. Our model covers both types of adjustment cost Uzawa[ 1965]'s Penrose effect type and E isner and Strotz[ 1963]'s type. First, the system is shown to be globally stable (Theorem 1). Then, Theorem 2 shows that if the per capita capital stocks of both countries increase over time or the capital stock of the foreign country increases while that of the home country decreases, and if the home country is rich in both initial physical capital endowments and foreign assets, then the home country either initially exports goods but eventually becomes an importer or she always imports goods. In either case she remains a creditor. (JEL Classification: F21, 012)
\end{abstract}


simplest possible frame-work. We assume one commodity is produced within two countries who use identical technologies and possess identical preferences under perfect competition over an infinite time horizon. Oniki and Uzawa [1965] analyzed the long run patterns of trade and investment assuming a specific saving function, while Findlay [1970] and Fischer and Frenkel [1972] developed a similar approach. Stiglitz [1970], on the other hand, first discussed the same topics assuming households display dynamic optimizing behavior. Sachs [1982], Lipton and Sachs [1983], Frenkel and Razin [1985], Diajic [1987], B lanchard and Fischer [1989], Turnovsky and Sen [1991], Ghosh [1992], Ikeda and Ono [1992], and Ono and Shibata [1992], among others, discussed the trade balance and asset-debt position over time employing similar methods. The OLG model was utilized by Buiter [1981], Obstfeld [1989] and Ihori [1991].

In the Ramsey type model describing the optimal growth of a one good economy, both the demand for and supply of investment are perfectly elastic. In particular, the demand for investment becomes passive. This implies that in the open economy without investment adjustment costs, the marginal products of capital of both countries are equal to the (common) interest rate plus the depreciation rate of capital. If both countries have identical technologies, identical rates of population growth and identical preferences, then the capital-labor ratios of both countries and per capita investment and consequently the accumulation rates of per capita capital are all equalized after an initial change (jump) in the capital-labor ratio caused by the opening of trade. However, these three quantities are not equalized in the real world, raising rather serious doubts concerning the validity of the Ramsey model in an open economy.

Another concern with the Ramsey type model is the inseparability between the saving decision and investment decision, as noted by Abel and 
into the analysis of dynamic trade imbalances.

Another way to avoid the above inseparability would be to introduce an investment good, thus generating an investment supply function per U zawa [1964]. However in an open economy without adjustment costs, if both the consumption good and the investment good are traded, and if there are two factors of labor and capital with identical technologies under perfect competition, then both countries' capital rental prices are equalized independent of the amounts of factor endowment and the international allocation of capital stock becomes indeterminate. This is the same indeterminacy of trade patterns caused by international capital mobility analyzed by M undell [1957]. By introducing adjustment costs we can avoid this indeterminacy. Ghosh [1992] avoided such an indeterminacy in a two good economy without adjustment costs by assuming perfect specialization of production. Lipton and Sachs [1983] adopted a simulation approach using a model of a two good economy with investment adjustment costs. U pon reviewing these references, it seems apparent that the dynamic patterns of trade imbalance and asset-debt position are most fully analyzed employing the two good framework with investment adjustment costs. As a first approximation towards such a model, a one-good open economy case is analyzed first.

\section{Model}

Let there be two countries, the home country and the foreign country, both of which have identical preferences (utility functions) of constant relative risk aversion (CRRA) and identical production functions of constant returns to scale which utilize two factors; labor and capital. The populations of both countries are assumed to grow at the same rate, $n .{ }^{1}$ Assume that only one good is produced and that it can be used as both a consumption 


$$
\pi=f(k)-w-i
$$

where $f(k)$ is the per capita gross domestic product (GDP), $k$ is per capita capital - hereafter all lowercase letters define per capita terms - $w$ is the wage rate and $i$ is the amount of investment. $f$ is a strictly concave labor productivity function. Hence the instantaneous net cash flow $\pi$ is the GDP less the wage rate and investment. The following is the equation of the motion of capital;

$$
\dot{\mathrm{k}}=\mathrm{kg}(\mathrm{i} / \mathrm{k})-(\mathrm{n}+\mathrm{)} \mathrm{k}
$$

where $\dot{k}$ is the time rate of change of capital $k$ ( $\dot{x}$ is the time rate of change of $x$.), the function $g$ reflects the adjustment cost of investment which is increasing and concave with $g(0)=0, g^{\prime}(0)=1, g^{\prime}>0$, and $g^{\prime \prime}<0$. Let $\delta>0$ be the rate of capital depreciation. The function $g$ implies that as investment $i$ increases relative to a given $k$, the net increase in $\dot{k}$ declines due to the increase in the adjustment cost (The variables are functions of time. Time dependency is not expressed for simplicity of notation). The function $\mathrm{g}$ was first introduced by Uzawa [1965] to represent the Penrose effect. (We term it g-type adjustment cost.) Another way to express the net cash flow is the following;

$\pi$ is expressed as

$$
=f(k)-w-i(1+h(i / k)) \text {. }
$$

The adjustment cost of investment is represented by the function $h$ which is increasing with $2 h^{\prime}+h^{\prime \prime} x>0$. (We term it h-type adjustment cost.) The equation of the motion of capital corresponding to this type of adjustment cost is expressed as;

$$
\dot{\mathrm{k}}=\mathrm{i}-(+\mathrm{n}) \mathrm{k} \text {. }
$$


to reflect the adjustment cost. ${ }^{2} \mathrm{~L}$ abor is paid the wage rate $w$ which is equal to the marginal product of labor $f(k)-k f^{\prime}(k)$ so that;

$$
w=f(k)-k f^{\prime}(k) \text { holds. }
$$

Over time the firm tries to maximize the net cash flow (1) or (1)' subject to the constraint (2) (respectively (2)') given the streams of interest rate $\{r(t)\}_{0}^{\infty}$ and wage rate $\{w(t)\}_{0}^{\infty}$. Henceforth we analyze only the g-type adjustment cost case. The results of the h-type cost case are shown in Appendix III. The maximized net cash flow (value of the firm) $\mathrm{V}\left(\mathrm{k}_{0} ; 0\right)$ at time 0 (the initial time) incorporating g-type cost is expressed as;

$$
V\left(k_{0} ; 0\right)=\max _{k} \int_{0}^{\infty}(f(k)-i-w)(0,) d
$$

given $r$ where $(0, \quad)=e^{-\int_{0}(r(s)-n) d s}$ is the discount rate from time 0 to time $\tau$. $r(s)$ is the (common) interest rate at time $s$ and $k_{0}$ is the initial capital endowment of the home country at the initial time 0 .

Abel and Blanchard [1983] regard the wage rate stream $\left\{w_{t}\right\}_{t=0}^{\infty}$ as given exogenously, and they actually maximiz $\oint_{0}^{\infty}(f(k)-i)(0)$,$d or \int_{0}^{\infty}[f(k)-$ $i(1+h(x))](0)$,$d . Hence formally our analysis is similar to theirs. In short$ the firm is a maximizer of net cash flow over time, given the stream of interest rates and wage rates. The corresponding cur rent value Hamiltonian for g-type cost is expressed as

$$
H(k, i, q)=f(k)-i-w+q[k g(i / k)-(n+) k]
$$

The first order conditions for maximization are;

$$
H_{i}=-1+q g^{\prime}=0
$$

and

$$
\dot{q}=-H_{k}+q(r-n)=-f^{\prime}-q\left(g-g^{\prime} \cdot x--r\right)
$$


for the g-type adjustment cost where $c$ is the amount of consumption and ex is the amount of exports. The gross national product, gnp is expressed as; gn $p=g d p+(r-n) a$ where $a$ is the amount of foreign asset held by the home households. Saving $s$ is $s=$ gnp $-c$.

Hence the time rate of change of assets, $a$ is;

$\dot{a}=$ current account surplus $=\mathrm{s}-\mathrm{i}$ for the g-type cost.

〈See Blanchard and Fischer [1989], p. 60.〉

Let $\beta$ and $\beta^{*}$ be respectively the proportions of the world population living in the home country and the foreign country. $\left(0<\beta, \beta^{*}<1, \beta+\beta^{*}=1\right.$ and $\beta$ and $\beta^{*}$ are constant over time. Hereafter an asterisk $*$ is added to indicate the variables and parameters of the foreign country.) Let $c_{-}=\beta c+\beta^{* *} c^{*}$ be the average consumption of the world. Then for the world economy we obtain;

$$
c=f(k)+{ }^{*} f\left(k^{*}\right)-i-{ }^{*} i^{*} \text { for the g-type cost. }
$$

\section{B. Utility Maximization by Consumers}

Next we consider the utility maximization. Let $\mathrm{U}$ be;

$$
U(c)=\max _{\dot{a}} \int_{0}^{\infty} u(c) e^{-(-n)} d
$$

subject to;

$$
\dot{a}=f(k)-c-i+(r-n) a \quad \text { for the g-type cost. }
$$

That is, the instantaneous utility function $u(c)$ is maximized over time subject to the budget constraint (9) where $\theta$ is the discount rate, which is assumed to be larger than the rate of population growth $n$, i.e., $\theta>n$. The change in asset $a$ is the results of exports, $e x=f(k)-c-i$ for the g-type cost and of interest revenue $(r-n) a$. By constructing the cur rent value Hamil- 
for the g-type adjustment cost. From the above conditions and the assumption of CRRA of the utility function $--u^{\prime} / u^{\prime \prime} \cdot c=\sigma>0$ being both a constant and the degree of relative risk aversion - we obtain;

$$
\hat{c}=-(-r)
$$

for the g-type adjustment cost where $\hat{c}=\dot{c} / c$. (Hereafter $\hat{x}=\dot{x} / x$.) For (9), the transverality condition $\lim _{t \rightarrow \infty} p(t) a(t) e^{-t-n) t}=0$ and $p(t)=p(0) e^{-\int_{0}^{t}(r-) d s}$ obtained from (12) implies the No-Ponzi-Game (NPG) condition;

$$
\lim _{t \rightarrow \infty} a(t) \quad(0, t)=0 .{ }^{3}
$$

The budget constraint ( 9 ) is rewritten as

$$
\dot{a}=+w-c+(r-n) a,
$$

from which we obtain

$$
a(t)=a\left(t_{1}\right) \quad\left(t, t_{1}\right)+\int_{t_{1}}^{t}(+w-c)(t,) d .
$$

By letting $t_{1} \rightarrow \infty$, from the NPG condition it follows that

$$
a(t)=f_{t}^{\infty}(+w-c)(t,) d \text {, }
$$

which implies;

$$
\int_{t}^{\infty} c()(t,) d=a(t)+F(k(t), t)=m(t)
$$

where $F(k(t), t)=\int_{t}^{\infty}(f(k)-i)(t)$,$d for the g-type cost is the sum of firm$ value $V(k(t), t)$ and human capital $H(t)=\int_{t}^{\infty} W(t)$,$d at time t$, and $m(t)$ is the gross national wealth at time $t$. (15) is another version of the home country's budget constraint. Note that the budget constraint (15) holds at any time t. From (13) and (15) it is easy to see that the demand function for the consumption good is expressed as $c=h(t) \cdot m(0)$ and $c^{*}=h(t) \cdot m^{*}(0)$, for $c / c^{*}$ 
lows that

$$
F\left(k_{0}, 0\right)>F\left(k_{0}^{*}, 0\right) .^{5}
$$

Furthermore we assume that the home country holds foreign assets initially $(a(0)>0)$, so that;

$$
m(0)>m^{*}(0) \text {, }
$$

i.e., the home country is initially rich in national wealth. Then we observe;

$$
c / c^{*}=m(0) / m^{*}(0)=b>1
$$

i.e., $c / c^{*}$ is constant over time.

Net cash flow maximization by firms and utility maximization by consumers constitute the decentralized world economy.

\section{Uniqueness of the Stationary State of the World Economy}

Here we observe the uniqueness of the stationary state of the world decentralized economy;

For the g-type cost case from (2) with $\dot{k}=0$, we obtain;

$$
\mathrm{g}\left(\mathrm{x}_{\infty}\right)=\mathrm{n}+.
$$

Then from (5) $q_{\infty}=1 / g^{\prime}\left(x_{\infty}\right)$ is derived. Next, from (6) with $\dot{q}=0$, we observe;

$$
x_{\infty}-f^{\prime}\left(k_{\infty}\right)=q_{\infty}\left(g\left(x_{\infty}\right)--\right) \text {. }
$$

F urthermore, $r_{\infty}=\theta$ from (13) with $\dot{c}=0, k_{\infty}=k_{\infty}^{*}, x_{\infty}=x_{\infty}^{*} i_{\infty}=i_{\infty}^{*}$ and $F\left(k_{\infty}, 0\right)=$ $F\left(k_{\infty}^{*}, 0\right)$ follow. From (16), it follows that $c_{\infty}>c_{\infty}^{*}$, hence $a_{\infty}>0$, and $e x_{\infty}<0<$ $e_{\infty}^{*}$. These show the uniqueness of the world equilibrium (stationary state).

Next we show that the above equilibrium constitutes a local saddle point Since $r_{\infty}=\theta$ holds for the g-type cost, (6) is expressed as 
near equilibrium. Then together with (2) and (5), we observe that $\left(k_{\infty}, q_{\infty}\right)$ is a local saddle point by forming the following phase diagram;

Figure 1

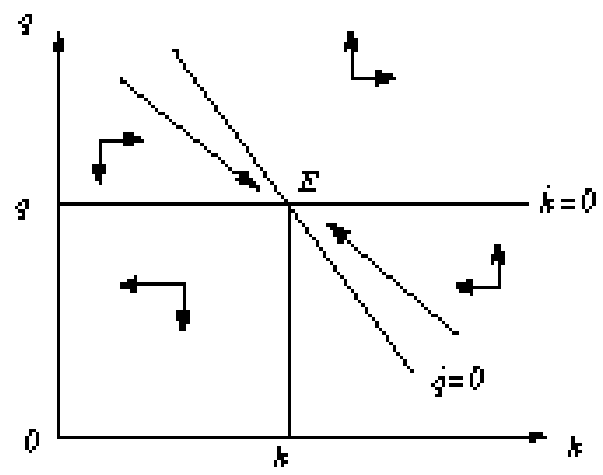

where the solid lines show the optimal path with $q=q(k), q^{\prime}(k)<0$. Note here that we can make use of the phase diagram technique because $r_{\infty}=\theta$ can be employed and hence the system of differential equations becomes autonomous near the stationary state. The same results also follow for the foreign country.

N ext, we consider the following system of differential equations for the $g$ type cost near the stationary state;

$$
\begin{aligned}
& \dot{k}=g(x(k)) \cdot k-(n+) k, \\
& \left.\dot{k}^{*}=g\left(x k^{*}\right)\right) \cdot k^{*}-(n+) k^{*}
\end{aligned}
$$

where $x(k)=x(q(k))$ and $x\left(k^{*}\right)=x\left(q\left(k^{*}\right)\right)$ with $x^{\prime}(k)=x^{\prime}(q) \cdot q^{\prime}(k)<0$ and $x^{\prime}\left(k^{*}\right)=$ $x^{\prime}\left(q^{*}\right) \cdot q^{\prime}\left(k^{*}\right)<0\left(q^{*}=q\left(k^{*}\right)\right)$. 


\section{Figure 2}

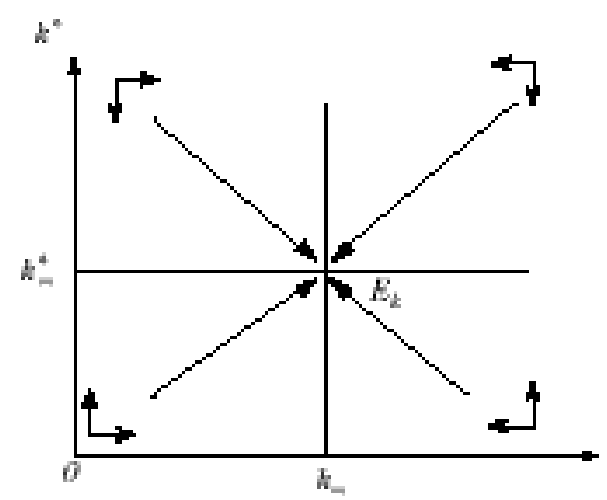

does not make sense to analyze local properties. Besides, such a case of local analysis does not produce a satisfactory treatment of transitional dynamics. It is therefore desirable to analyze the global properties of the world economy. To do so, we first want to show that $E_{k}$ is also a global stable point. In order to show the global stability of the economy, the following controlled economy is first introduced. This is necessary because the system of differential equations for the decentralized economy, (2), (6), (13) and their foreign counterparts are not autonomous, and hence stability analysis using phase diagrams can not be employed. However, by constructing the following controlled world economy which is equivalent to the decentralized world economy, we can analyze the global stability by manipulating the autonomous differential equations à la Able and Blanchard [1983].

\section{Controlled Economy}


$p\left(\beta f(k)+\beta^{*} f\left(k^{*}\right)-\beta c-\beta^{*} c^{*}-\beta i-\beta^{*} i^{*}\right)$, we obtain the following first order conditions for the g-type case;

$$
\begin{aligned}
& u^{\prime}-p=0 \\
& u^{* \prime}-p=0 \\
& Q g^{\prime}=p \\
& Q^{*} g^{* \prime}=p \\
& Q^{\prime}=\left(Q g^{\prime}\left(x-f^{\prime}\right)\right)-Q(g--) \\
& Q^{*}=Q^{*} g^{*^{\prime}}\left(x^{*}-f^{*^{*}}\right)-Q^{*}\left(g^{*}--\right)
\end{aligned}
$$

By setting $p^{*}=p / \gamma, Q=p q$ and $Q^{*}=p q^{*}$ for the $g$-type cost case, we observe (6) and (12) imply (22), and also the foreign counterparts of (6) and (12) imply (23). Furthermore by setting $\gamma=b^{-\sigma}$ the equivalence between (11) and (18), the equivalence between their foreign counterparts, the equivalence between (5) and (20), and the equivalence between their foreign counterparts are all immediate. ${ }^{6,7}$ For this controlled world economy, the system of differential equations (2), and its foreign counterpart, and (22) and (23) constitute autonomous equations for the g-type case.

Now let

$$
W\left(k_{t_{0}}, k_{t_{0}}^{*}\right)=\max _{k, k^{*}} \int_{t_{0}}^{\infty}\left\{u(c)+{ }^{*} u\left(c^{*}\right)\right\} e^{-(-n)\left(t-t_{0}\right)} d t
$$

be the present value of the maximized world utility where $\mathrm{k}_{\mathrm{t}_{0}}=\mathrm{k}\left(\mathrm{t}_{0}\right)$ and $\mathrm{k}_{\mathrm{t}_{0}}^{*}=\mathrm{k}^{*}\left(\mathrm{t}_{0}\right)$. Then the function $\mathrm{W}$ is increasing and concave in $\left(\mathrm{k}_{\mathrm{t}_{0^{\prime}}} \mathrm{k}_{\mathrm{t}_{0}}^{*}\right)$ and $\beta \mathrm{Q}=\partial \mathrm{W} / \partial \mathrm{k}_{\mathrm{t}_{0}}$ and $\beta^{*} \mathrm{Q}^{*}=\partial \mathrm{W} / \partial \mathrm{k}_{\mathrm{t}_{0}}^{*}$ holds. (See Appendix I.)

Note the function $W$ does not depend on time texplicitly since the above system of four differential equations are autonomous. $\langle\mathrm{F}$ or this, see, e.g., Léonard and Ngo [1992], Chapter 9〉. Then we observe that for g-type case,

$$
\mathrm{Q}=\mathrm{Q}\left(\mathrm{k}_{\mathrm{t},}, \mathrm{k}_{\mathrm{t}_{0}}^{*}\right) \text { and } \mathrm{Q}^{*}=\mathrm{Q}^{*}\left(\mathrm{k}_{\mathrm{t}^{\prime}}, \mathrm{k}_{\mathrm{t}_{0}}^{*}\right)
$$


hold for given $\left(\mathrm{k}_{\mathrm{t}^{\prime}}, \mathrm{k}_{\mathrm{t}_{0}}^{*}\right)$. Since $\left(\mathrm{k}_{\mathrm{t}_{0}}, \mathrm{k}_{\mathrm{t}_{0}}^{*}\right)$ are arbitrary, it follows that in general

$$
\mathrm{Q}=\mathrm{Q}\left(\mathrm{k}, \mathrm{k}^{*}\right), \mathrm{Q}^{*}=\mathrm{Q}^{*}\left(\mathrm{k}, \mathrm{k}^{*}\right) \text { with } \mathrm{Q}_{\mathrm{k}}<0 \text { and } \mathrm{Q}_{\mathrm{k}^{*}}^{*}<0 \text {. }
$$

Now for the g-type case, from (7), (18), (19), (20) and (21), we observe that $x$ and $x^{*}$ depend on $\left(Q, Q^{*}, k, k^{*}\right)$, and hence on $\left(k, k^{*}\right)$. Then the above system of four differential equations are reduced to that of two differential equations;

for the g-type case

$$
\left\{\begin{array}{l}
\dot{k}=g(x) \cdot k-(n+) k \\
k^{*}=g\left(x^{*}\right) \cdot k^{*}-(n+) k^{*}
\end{array}\right.
$$

with $x=x\left(k, k^{*}\right)$ and $x^{*}=x^{*}\left(k, k^{*}\right)$. To prove global stability, we employ the following lemma;

Lemma 1: (PoincaréBendixon Theorem 〈Hsu and M eyer [1968] Section 5.8〉

(1) For the two dimensional autonomous differential equation system, the path ( trajectory) must become unbounded or converge to a limit cycle or to a point.

(2) If a limit cycle exists, then the Poincaré index $\mathrm{N}-\mathrm{S}$ is 1 where $\mathrm{N}$ denotes the number of nodes, centers and foci enclosed by a limit cycle, and $S$ denotes the number of saddle points enclosed by a limit cycle.

First we show the boundedness of the optimal path. It suffices to show the path obtained by zero consumption is bounded. We consider the case of the g-type cost.

Let $k^{*}=0, c=c^{*}=0$ and $x_{-}^{*}$ be $x^{*}$ such that $g\left(x^{*}\right)=n+\delta$. Then from (7) it follows that

$$
\beta f(k)+\beta^{*} a=\beta x k+\beta^{*} x_{-}^{*} k^{*}
$$


Figure 3

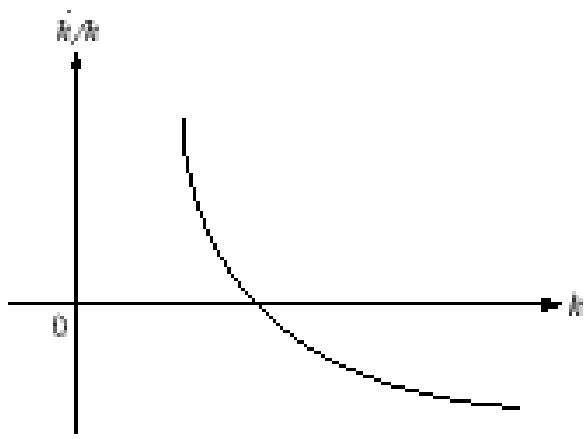

Figure 4

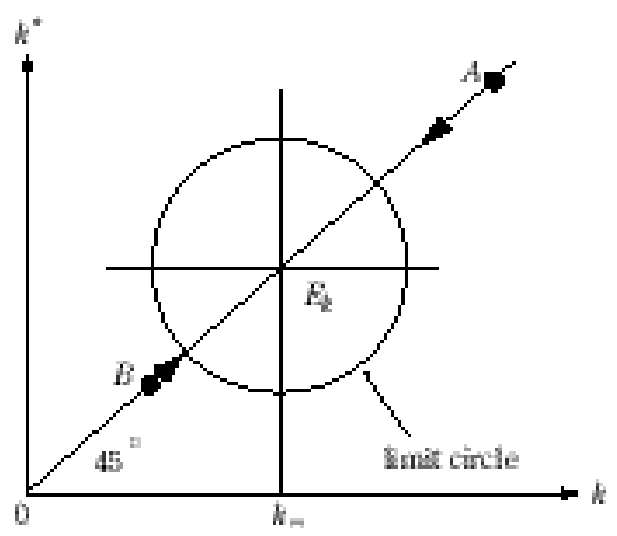

$\beta f(k)+\beta^{*} f\left(k^{*}\right)=\beta x k$, 
limit cycle, contradicting (1) of Lemma 1. N ow we consider the case where the initial points are located outside the limit cycle such as points $A$ and $B$ in Fig. 4. (18) through (23) also imply that the world's average utility $u\left(\beta c+\beta^{*} C^{*}\right)$ is maximized over time subject to (2), its foreign counterpart and (7) for the g-type adjustment costs. ${ }^{8}$

Given $k, k^{*}, c_{-}$and $i_{-}=\beta i+\beta^{*} i$, the world's average capital accumulation rate $k \angle k$ has to be maximized under the optimal path of $c_{-}$from the production efficiency consideration ( where $k_{-}=\beta k+\beta^{*} k^{*}$ ). That is, when $k=k^{*}$ holds initially for the g-type case

$$
\begin{aligned}
\dot{\bar{k}} / \overline{\mathrm{k}} & =\left(\dot{\mathrm{k}}+{ }^{*} \dot{\mathrm{k}}^{*}\right) / \overline{\mathrm{k}} \\
& =\dot{\mathrm{k}} / \mathrm{k}+{ }^{*} \mathrm{k}^{*} / \dot{\mathrm{k}} \\
& =g(\mathrm{i} / \mathrm{k})+{ }^{*} \mathrm{~g}\left(\mathrm{i}^{*} / \mathrm{k}^{*}\right)-(\mathrm{n}+) \\
& =g(\mathrm{i} / \mathrm{k})+{ }^{*} \mathrm{~g}\left(\mathrm{i}^{*} / \mathrm{k}^{*}\right)-(\mathrm{n}+) \\
& \leq \mathrm{g}(\mathrm{i} / \mathrm{k})+{ }^{*} g(i / k)-(\mathrm{i}+)
\end{aligned}
$$

from $\beta \mathrm{i}+\beta^{*} \mathrm{i}^{*}=\mathrm{i}$ and the concavity of the function $\mathrm{g}$. In short, when $\mathrm{k}=\mathrm{k}^{*}$, holds initially, $k \_k \_$is maximized when $i=i^{*}=i$ holds. Hence we observe that when $k=k^{*}$ holds initially, $i=i^{*}$ must follow. This further implies $x=x^{*}$ and $Q=Q^{*}$ when $k=k^{*}$ holds initially. Hence $\dot{k}=\dot{k}^{*}$ follows. That is, when $k=k^{*}$ holds initially, the capital of both countries changes at the same rate since $\mathrm{dk}^{*} / \mathrm{dk}=1$ holds. In Fig. 4 this implies that points $A$ and $B$ move along line $0 A$ (the $45^{\circ}$ degree line) towards $E_{k}$. Hence we observe that there cannot be any limit cycle surrounding the stationary point $E_{k}$, and any optimal path starting from an arbitrary point must converge to the stable node $E_{k}$, showing the global stability of the world economy. In short,

\section{Theorem 1;}

The world economy has gl obal dynamic stability for the g-type adjustment cost. 
$k_{0}=k_{0}^{*}$ is assumed only to prove global stability. Elsewhere $k_{0}>k_{0}^{*}$ is assumed when analyzing dynamic trade patterns. In view of Theorem $\mathbf{1}$, for the g-type case, $k^{*}$, when on the optimal path, is seen to depend only on $k$, so that $k^{*}=k^{*}(k)$ holds. Then from $x=x\left(k, k^{*}\right)$, we observe that

$$
x=\tilde{x}(k)=x\left(k, k^{*}(k)\right) \text { holds. }
$$

\section{E. Trade Patterns and Asset-Debt Positions}

Next we consider trade patterns and their corresponding asset-debt positions. First we show that the interest rate $r$ can be regarded as being dependent only on $k$ or $k^{*}$. In fact by substituting (2) and (6) into $\hat{q}=-\left(g^{\prime} / g^{\prime \prime}\right) \widehat{x}^{\prime} \dot{k}^{\prime}$, obtained by totally differentiating (5) with $x=-\widetilde{x}(k)$, we observe that $r$ depends only on $k$ for the g-type case. Then $x=x(q)$ can be obtained from (5) and $r=r(k) .{ }^{9}$ Hence (6) can be expressed as;

$$
\begin{aligned}
& \dot{q}=x(q)-f^{\prime}(k)-q(g(x(q))-r(k)-) . \\
& \dot{k}=k g(x(q))-(n+) k .
\end{aligned}
$$

(24) and (2) constitute the system of two dimensional autonomous differen-

\section{Figure 5}

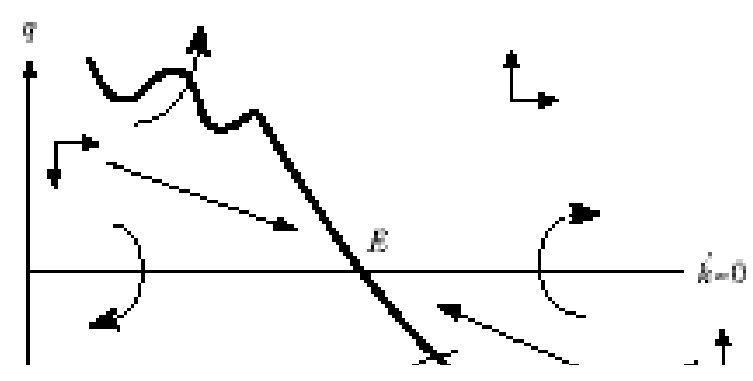




\section{Figure 6}

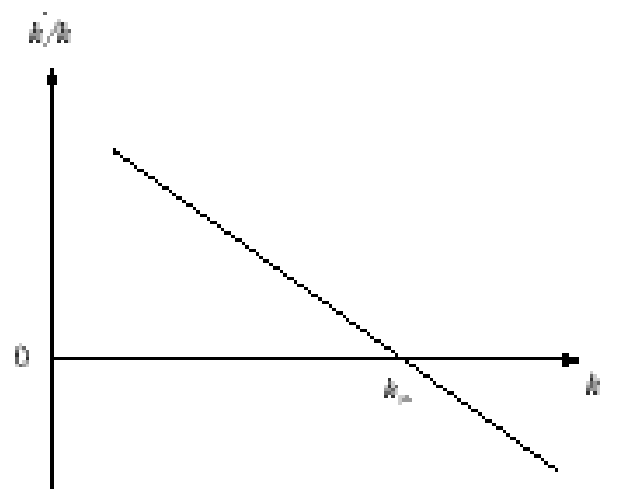

tial equations for the g-type case.

Since $r_{\infty}=\theta>n$, and $g\left(x_{\infty}\right)=n+\delta$ hold for the g-type case, we observe that $r_{\infty}>g\left(x_{\infty}\right)-\delta$. We generalize slightly and assume that;

A. $1 r>g(x)-\delta$ for the g-type case

From A.1 we observe that $E$ is the saddle point of the phase diagram obtained from the above two autonomous differential equations and along the optimal path for the g-type case

$$
q=q(k) \text { with } d q / d k<0^{10} \text { holds. }
$$

Similarly for the foreign country

$$
\mathrm{q}^{*}=\mathrm{q}\left(\mathrm{k}^{*}\right) \text { with } \mathrm{dq}^{*} / \mathrm{dk}^{*}<0^{11}
$$

holds. From (5) with, we observe that;

$x=x(q)$ with $d x / d k>0$. 
Hence $x=x[q(k)]$ with $d x / d k<0$. Then from (2) we obtain;

$$
\mathrm{d}(\dot{\mathrm{k}} / \mathrm{k}) / \mathrm{dk}<0 \text {. }
$$

The two countries are assumed to be identical except for the initial endowment of capital and assets. Initially the home country is endowed with more capital than the foreign country so that $k_{0}>k_{0}^{*}$ where $k_{0}^{*}$ is the initial capital endowment of the foreign countr $y$. As is seen, $q$ and $q^{*}$ are expressed as $q=q(k)$ and $q^{*}=q\left(k^{*}\right)$ with $q^{\prime}$ and $q^{*_{1}}<0$. Then $E q$. (2) and its foreign counterpart imply that $\dot{k} / k<\dot{k}^{*} / k^{*}$ holds always and hence

$$
k(t)>k^{*}(t)
$$

holds always with $k_{\infty}=k_{\infty}^{*}$. This is also observed from Fig. 4, since any optimal path of $\left(k, k^{*}\right)$ with $k \neq k^{*}$ initially moves monotonically toward $E_{k}$ without passing through the $45^{\circ}$ line $0 \mathrm{~A}$. We have observed that

$$
g\left(x_{\infty}\right)=n+\delta \text { and } q_{\infty}=1 / g^{\prime}\left(x_{\infty}\right) \text { from (5), }
$$

and

$$
x_{\infty}-f^{\prime}\left(k_{\infty}\right)=q_{\infty}\left(g\left(x_{\infty}\right)-q-\delta\right) .
$$

Hence $\theta>n$ implies $f^{\prime}\left(k_{\infty}\right)>x_{\infty}$. We slightly generalize the above two inequalities and assume;

A. $2 f^{\prime}(k)>x$ always holds along the optimal path for the g-type adjustment costs. ${ }^{12}$

There exist three possible cases of capital accumulation for the world economy;
(1) $\mathrm{k}_{0}^{*}<\mathrm{k}_{0}<\mathrm{k}_{\infty}$, and hence $\dot{\mathrm{k}}>0 \dot{\mathrm{k}}^{*}>0$
(2) $k_{\infty}<k_{0}^{*}<k_{0}$, and hence $\dot{k}<0 \dot{k}^{*}<0$
(3) $k_{0}^{*}<k_{\infty}<k_{0}$, and hence $\dot{k}<0 \dot{k}^{*}>0$. 
stock of the home country decreases but that of the for eign country increases.

Now we consider the direction of the change in exports, ex, over time. First we consider the change in the net production $n p=f(k)-i$ for the $g$ type case. Then from $\mathrm{i}=\mathrm{xk}$ we obtain;

$$
n \dot{p}=\left(f^{\prime}(k)-x\right) \dot{k}-k \dot{x} \text { for the g-type case. }
$$

Here from $x=x(q(k))$ and $d q / d k<0$, we observe

$$
\dot{x}<0 \Leftrightarrow \dot{k}>0 \text {. }
$$

Hence under A. 2, it follows that;

$$
n \dot{p}>0 \Leftrightarrow \dot{k}>0 .
$$

Here we fur ther assume that;

A. 3; $\ddot{n} \ddot{p}<0$ if $\dot{k}>0$, i.e., $n p$ is increasing but less and less over time when the capital stock also increases over time. ${ }^{13}$

Fig. 7 shows the np function for 9 -type case under A. 3. Two points $A$ and $A^{*}$ show the respective positions of the home country and the foreign country at a particular point of time.

Under A. 3, we observe at any time, when $\dot{k}>0$ holds;

\section{Figure 7}

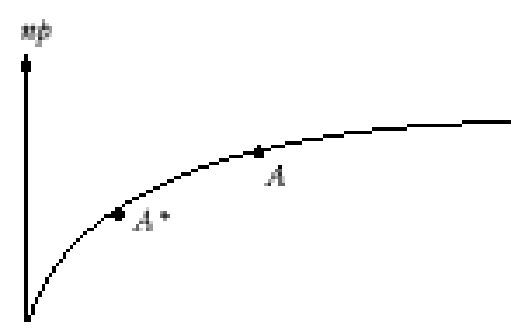


$f^{\prime} \dot{k}-\dot{i}<f^{*} k^{*}-i^{*}$ for the g-type case

follows. Employing this, we obtain;

\section{Theorem 2:}

(1) For $k_{0}^{*}<k_{0}<k_{\infty}\left(i . e ., \dot{k}, k^{*}>0\right)$

under A. 3, ex $<0$ i.e., the home country's exports decrease over time or the home country's imports increase over time. More specifically either (i) the home country initially exports goods, gradually decreases its exports, and then becomes an importer of goods and stays so afterward, or (ii) the home country initially imports goods and remains an importer afterward. In either case, the home country remains a creditor, i.e., a $(\mathrm{t})>0$ always.

(2) For $k_{\infty}<k_{0}^{*}<k_{0}\left(i . e ., \dot{k}, k^{*}<0\right)$

the dynamic patterns of trade and the asset-debt position are indeterminate.

(3) For $\mathrm{k}_{0}^{*}<\mathrm{k}_{\infty}<\mathrm{k}_{0}\left(\right.$ i.e., $\left.\dot{\mathrm{k}}<0<\mathrm{k}^{*}\right)$

ex $<0$, and the dynamic patterns of trade imbalance and asset-debt position are the same as (1). (A. 3 is not required here.)

Proof: See Appendix II.

The indeterminacy of dynamic trade patterns, ( $\operatorname{sgn}$ ex) for (2) $k_{\infty}<k_{0}^{*}<k_{0}$ (i.e., $\dot{k}<0$ and $\dot{k}^{*}<0$ ) cannot be avoided even if the corresponding assumption on net production, $\mathrm{np}$ is made; i.e., $\mathrm{n} p<0$ and $\mathrm{n} p$ cussion is in Appendix II.)

The most interesting case is ( 1$) k_{0}^{*}<k_{0}<k_{\infty}$ (i.e., $\dot{k}<0$ and $\dot{k}^{*}>0$ ) where the both countries accumulate capital and both countries' consumption and net production increase over time. For this case, even if the home country is rich in assets and wealth initially and may export initially, she becomes an 
the home country becomes an importer of goods. $c>c^{*}$ near the stationar $y$ state means that the home countr y remains a creditor, i.e., $a>0$.

Here we would like to highlight two differences between our model and Blanchard and Fischer [1989]'s model. Although we have built upon their model, our approaches differ. They analyze local patterns of trade and asset-debt positions around a stationary state while we analyze their global properties. This difference arises because our analysis is based on Tobin's $q$ (costate variable of capital) which globally is a decreasing function of $k$ only.

\section{Concluding Remarks}

The dynamic trade pattern and asset-debt position are based on the global stability of the world capital accumulation path, without which the analysis would be limited to be the area near the stationary state. A fuller model would be a two traded good (one consumption good and one investment good) economy with adjustment costs which I would like to investigate next.

\section{References}

Abel , Andrew B. and Olivier J. B lanchard [1983], "An Intertemporal M odel of Saving and Investment," E conometrica 51; pp. 675-692.

Arrow, Kenneth A. and M ordecai Kurz [1970], Public Investment, The Rate of Reform, and Optimal Fiscal Policy, (J ohns Hopkins Univ. Press, Baltimore)

Blanchard, Olivier ] . and Stanley Fischer [1989], "Consumption and Investment: Basic Infinite Horizon M odels," in Lectures on Macroeconomics 
Borrowing in an Overlapping - Generations Model," Journal of Politi cal Economy 89; pp. 760-797.

Djajic, Slobodan [1987], "Effects of Budgetary Policies in O pen Economies: The Role of Intertemporal Consumption Substitution," Journal of Inter national Money and Finance 6; pp. 373-383.

Eisner, Robert and Robert H. Strotz [1963], "Determinants of Business Investment," in D.B. Suits et al. eds., Commission on M oney and Credit: Impacts of M ontary Policy (Prentice Hall, Englewood Cliffs, N. J.)

Findlay, Ronald [1970], "F actor Proportions and Comparative Advantage in the Long Run," Journal of Political Economy 78; pp. 27-34.

Fischer, Stanley and J acob A. Frenkel [1972], "Investment, the Two-Sector Model and Trade in Debt and Capital Goods," Journal of I nternational Economics 2; pp. 211-233.

Frenkel, Jacob A. and Assaf Razin [1985], "Government Spending, Debt, and International Economic Interdependence," Economic Journal 95; pp. 619-636.

Ghosh, Atish R. [1992], "Fiscal Policy, the Terms of Trade, and the External Balance," Journal of International E conomics 33; pp. 105-125.

Gould, John P. [1968], "Adjustment Cost in the Theory of Investment of the Firm," Review of Economic Studies 35; pp. 47-55.

Hsu, Jay C. and Andrew U. Meyer [1968], Modern Control Principles and Applications (M cGrawHill, N ew York).

Hayashi, Fumio [1982], “Tobin's M arginal q and Average q: A N eoclassical Interpretation," Econometrica 50; pp. 213-224.

Ihori, Toshihiro [1991], "Capital Income Taxation in a World Economy: A Territorial System versus a Residence System," E conomic Journal 101; pp. 958-965.

Ikeda, Shinsuke and Yoshiyasu Ono [1992], “M acroeconomic Dynamics in a 
E conomics 15; pp. 135-159.

Lucas, Robert E. Jr. [1967], "Adjustment Costs and the Theory of Supply," Journal of Political Economy 75; pp. 321-334.

M undell, Robert A. [1957], "International Trade and Factor M obility," Amer ican Economic Review 47; pp. 321-335.

M ussa, M ichael [1977], "External and Internal Adjustment Costs and the Theory of Aggregate and Firm Investment," Economica 44; pp. 163178.

Obstfeld, M aurice [1989], "Fiscal Deficits and Relative Prices in a Growing World Economy," Journal of M onetary E conomics 23; pp. 461-484.

Oniki, Hajime and Hirofumi Uzawa [1965], "Patterns of Trade and Investment in a Dynamic M odel of International Trade," Review of Economic Studies 32; pp. 15-38.

Ono, Yoshiyasu and Akihisa Shibata [1992], "Spill-Over Effects of SupplySide Changes in a Two-Country Economy with Capital Accumulation," Journal of International E conomics 33; pp. 127-146.

Sachs, J effrey [1982], "The Current Account in the M acroeconomic Adjustment Process," Scandinavian Journal of E conomics 84; pp. 147-159.

Stiglitz, Joseph E. [1970], "Factor Price Equalization in a Dymanic Economy," Journal of Political E conomy 78; pp. 456-488.

Takayama, Akira [1994], "Infinite Horizon Optimization Control Problem and Applications," in Analytical Methods in Economics (Harvester Wheatsheaf, Hertfordshire, England).

Treadway, A. B. [1969], "On Rational Entrepreneurial Behaviour and the Demand for Investment," Review of E conomic Studies 36; pp. 227-239.

Turnovsky, Stephen J. and Partha Sen [1991], "F iscal Polity, Capital Accumulation, and Debt in an O pen E conomy," Oxford Economic Papers 43; pp. 1-24. 


\section{Appendix I}

\section{(1) Increasingness of the Function W with respect to the Initial Value of Capital Stock,}

i.e.,

$$
k_{1} \geq k^{0} \text { and } k_{1}^{*} \geq k^{* 0} \Rightarrow W\left(k^{0}, k^{* 0}\right) \leq W\left(k_{1}, k_{1}^{*}\right) \text {. }
$$

The following arguments hold for both g-type and h-type cases where $k^{0}=k_{t_{0}}, k^{* 0}=k_{t_{0}}^{*}$.

Let $k_{t}=k\left(t, k^{0}, k^{* 0}\right)$ and $k_{t}^{*}=k^{*}\left(t, k^{0}, k^{*}\right)$, and $i_{t}=i\left(t, k^{0}, k^{* 0}\right)$ and $i_{t}^{*}=i^{*}\left(t, k^{0}, k^{* 0}\right)$ be the optimal capital and investment at time $t$ given initial values $\left(k^{0}, k^{*}\right)$. Assue without loss of generality that $k_{1} \geq k^{0}$ and $\mathrm{k}_{1}^{*}=\mathrm{k}^{*}$. Consider the suboptimal path of investment such that at time $\mathrm{t}, \mathrm{i}_{\mathrm{t}}^{1}=\mathrm{i}_{\mathrm{t}}$ and $\mathrm{i}_{\mathrm{t}}^{* 1}=\mathrm{i}_{\mathrm{t}}^{*}$ given the initial value $\left(k_{1}, k^{*}{ }_{1}\right)$. Then in view of $(2),(2)^{\prime},(7)$ and $(7)^{\prime}$, clearly corresponding to this suboptimal path, it is possible to set $c_{t}^{1}$ and $c_{t}^{* 1}$ so that $c_{t}^{1} \geq c_{t}$ and $c_{t}^{* 1} \geq c_{t}^{*}$ for any $t \geq t_{0}$. In particular $c_{t}^{1}>c_{t}$ and $c_{t}^{* 1}>c_{t}^{*}$ hold for $t_{1}>t>t_{0}$ where $\left\{c_{t}, c_{t}^{*}\right\}_{t}^{\infty}=0$ are the optimal consumption path given $k^{0}$ and $k^{* 0}$. Clearly $W\left(k_{1}, k_{1}^{*}\right)$ is not less than $\int_{t_{0}}^{\infty}\left\{u\left(c_{t}^{1}\right)+{ }^{*} u\left(c_{t}^{* 1}\right)\right\} e^{-(-n)\left(t-t_{0}\right)} d t\left(>W\left(k^{0}, k^{* 0}\right)\right)$.

(2) Concavity of the Function $\mathrm{W}\left(\mathrm{k}^{0}, \mathrm{k}^{* 0}\right)$ in $\left(\mathrm{k}^{0}, \mathrm{k}^{* 0}\right)$. We provide the proof for the g-type case only, since the similar arguments can be employed for the h-type case. Although the following proofs are essentially given by Brock and Scheinkman [1977], we provide them here for completeness.

Let

$$
J\left(k, k^{*}, \dot{k}, \dot{k}^{*}\right)=\max _{c, c^{*}}\left\{u(c)+{ }^{*} u\left(c^{*}\right)\right\}
$$

subject to (2), its foreign counterpart, and (7). Then function $\mathrm{J}$ is concave in $\left(k, k^{*}, \dot{k}^{*}, k^{*}\right)$.

\section{Proof:}

$$
\text { Let } J\left(k, k^{*}, \dot{k}, \dot{k}^{*}\right)=u(c)+{ }^{*} u\left(c^{*}\right)
$$

and $J\left(h, h^{*}, \dot{h}, \dot{h}^{*}\right)=u(e)+{ }^{*} u\left(e^{*}\right)$

for a given $\lambda$ such that $0<\lambda<1$. Then $c_{2}$ and $c_{2}^{*}$ are defined as 
$\left(\bar{c}, \bar{c}^{*}\right)=\arg \max \left\{u(c)+{ }^{*} u\left(c^{*}\right)\right\}$

$$
\begin{aligned}
& G(i+(1-) j, \bar{k}) \geq G(i, k)+(1-) G(j, h) \text { and } \\
& G\left(i^{*}+(1-) j^{*}, k^{*}\right) \geq G\left(i^{*}, k^{*}\right)+(1-) G\left(j^{*}, h^{*}\right)
\end{aligned}
$$

and hence

$$
\begin{aligned}
& \dot{k} \leq G(i+(1-) j, k)-(n+) k, \\
& \dot{k} \leq G\left(i^{*}+(1-) j^{*}, k^{*}\right)-(n+) k^{*} .
\end{aligned}
$$

We observe

$$
\mathrm{i} \leq \mathrm{i}+(1-) \mathrm{j} \text { where } \dot{\mathrm{k}}=\mathrm{G}(\mathrm{i}, \mathrm{k})-(\mathrm{n}+) \mathrm{k},
$$

and

$$
i^{*} \leq i^{*}+(1-) j^{*} \text { where } \dot{k}^{*}=G\left(i^{*}, k^{*}\right)-(n+) k^{*} .
$$

Then we obtain

$$
\begin{aligned}
& \quad J\left(k, k^{*}, \dot{k}, \dot{k}^{*}\right)+(1-) J\left(h, h^{*}, \dot{h}, \dot{h}^{*}\right)=(u(c)+(1-) u(e)) \\
& +\quad\left(u\left(c^{*}\right)+(1-) u\left(e^{*}\right)\right) \leq u(\tilde{c})+{ }^{*} u\left(\tilde{c}^{*}\right)
\end{aligned}
$$

where $\tilde{c}=c+(1-) e \tilde{c}^{*}=c^{*}+(1-) e^{*}$, and $(f(k)+(1-) f(h))$

$+{ }^{*}\left(f\left(k^{*}\right)+(1-) f\left(h^{*}\right)\right)=\tilde{c}+{ }^{*} \tilde{c}^{*}+(i+(1-) j)$

$+{ }^{*}\left(i^{*}+(1-) j^{*}\right)$

Obser ving that by the concavity of $f$,

$$
f(k)+(1-) f(h) \leq f(k) \text { and } f\left(k^{*}\right)+(1-) f\left(h^{*}\right) \leq f\left(k^{*}\right)
$$

hold always and from $i \leq i+(1-) j$ and $i^{*} \leq i^{*}+(1-) j^{*}$,

we obtain from (A-1) and (A-2)

$$
C+{ }^{*} C^{*} \geq \tilde{C}+{ }^{*} \tilde{C}^{*}
$$




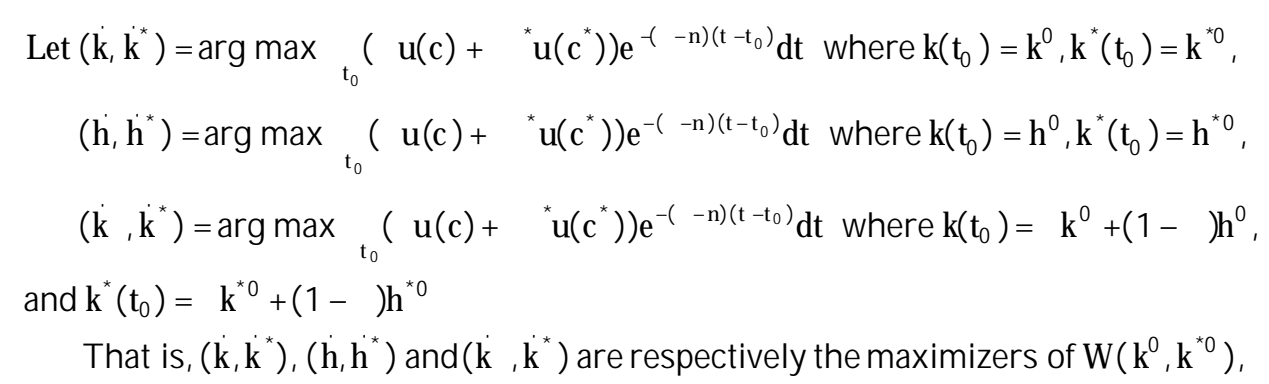

$W\left(h^{0}, h^{* 0}\right)$ and $W\left(k^{0}+(1-) h^{0}, k^{* 0}+(1-) h^{* 0}\right)$. Then

$W\left(k^{0}, k^{* 0}\right)+(1-) W\left(h^{0}, h^{* 0}\right)$

$=\int_{t_{0}}^{\infty} J\left(k, k^{*}, \dot{k}, \dot{k}^{*}\right) e^{-t-n)\left(t-t_{0}\right)} d t+(1-) \int_{t_{0}}^{\infty} J\left(h, h^{*}, \dot{h}, \dot{h}^{*}\right) e^{-t-n)\left(t-t_{0}\right)} d t$

$\leq \int_{\mathrm{t}_{0}}^{\infty} J\left(k+(1-) h, k^{*}(1-) h^{*}, \dot{k}+(1-) \dot{h}, \dot{k}^{*}+(1-) \dot{h}^{*}\right) e^{-(-n)\left(t-t_{0}\right)} d t$

$\leq \max _{\dot{k}+1-) \dot{h}^{*}+(1-) h^{*}} \int_{t_{0}}^{\infty} J\left(k+(1-) h, k^{*}+(1-) h^{*}, \dot{k}+(1-) \dot{h}, \dot{k}^{*}+(1-) \dot{h}^{*}\right)$
$=W\left(k^{0}+(1-) h^{0}, k^{* 0}+(1-) h^{* 0}\right)$

$\dot{e x}=f^{\prime} \dot{k}-\dot{i}-\dot{c}$ for the $g$-type case and

$\dot{e x}=f^{\prime} \dot{k}-\dot{i}(1+h)-i h^{\prime} \dot{x}-\dot{c}$ for the $h$-type case.

Obser ving $\dot{c}=\dot{c} \underline{c} / c_{-}$for the respective types, we obtain

$\dot{e x}=(1-c / \tau)\left\{\left(f^{\prime}-x\right) \dot{k}-\dot{x} k\right\}$

$-\left({ }^{*} c / \tau\right)\left\{\left(f^{* \prime}-x^{*}\right) k^{*}-\dot{x}^{*} k^{*}\right\}$ for the g-type case $(A-2)$

and

$\dot{e x}=(1-c / \tau)\left\{\left(f^{\prime}-(1-h) x\right) \dot{k}-i \dot{x}\right\}$

$-\left({ }^{*} \mathrm{c} / \mathrm{c}\right)\left\{\left(\mathrm{f}^{* \prime}-\left(1+\mathrm{h}^{*}\right) \mathrm{x}^{*}\right) \dot{\mathrm{k}}^{*}-\mathrm{i}^{*} \dot{\mathrm{x}}^{*}\right\}$ for the h-type case $(\mathrm{A}-2){ }^{\prime}$. 
These show the sgn of ex for ( 1 ) and (3). Since $c_{\infty}>c_{\infty}^{*}, k_{\infty}=k_{\infty}^{*}, i_{\infty}=i_{\infty}^{*}$ and $x_{\infty}=x_{\infty}^{*}, e x_{\infty}<0$, i.e., the home country eventually becomes an importer of the good and $a_{\infty}>0$ for all cases (1), (2) and (3).

For (1), since ex $<0$, either (i) the home country exports the good initially, and subsequently becomes an importer or (ii) the home country continues to import the good from the beginning.

Next observing the budget constraint

$$
\dot{a}=e x+(r-n) a
$$

and

$$
a(t)=f_{t}^{\infty} e x(t,) d
$$

where ex $=\pi+w-c$, the change in a(t) can be drawn roughly as follows;

For (1) - (i),

where ex $>0$ for a while implies that asset a increases.

At $t_{1}$, the home country becomes an importer of the good. When at $t_{2}$ the amount of imports, - ex exceeds $(r-n)$ a, i.e., $-e x>(r-n) a>0$, asset a begines to decline. From $(A-4)$, we observe $a(t)>0$ after $t_{1}$. Hence $a(t)>0$ always. (See Fig. (A-1).)

For (1) - (ii)

\section{Figure A-1}


the home country imports the gEiguffof -2 he beginning, so ex $<0$ for any $t$ and hence $a(t)>$

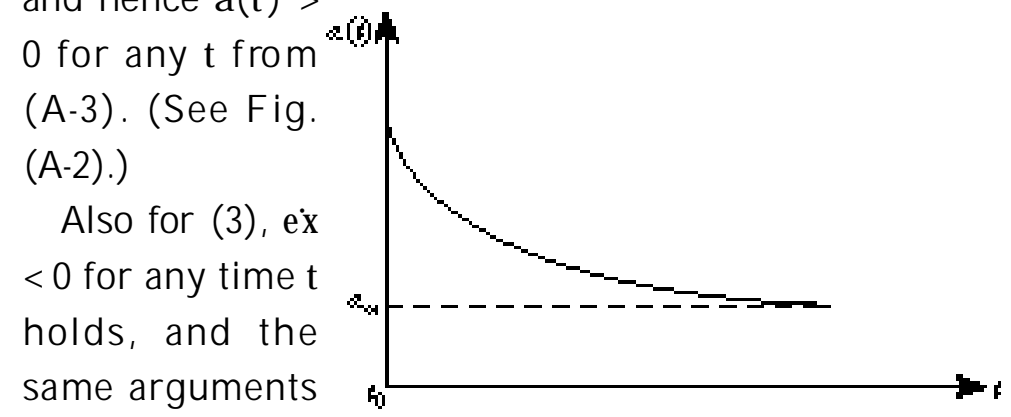

as above can be applied. For $(2), \mathrm{k}_{\infty}<\mathrm{k}_{0}^{*}<\mathrm{k}_{0}\left(\mathrm{k}<0\right.$ and $\left.\mathrm{k}^{*}<0\right)$ the assumption on np corresponding to $\mathbf{A} . \mathbf{3}$ is that $n p$ is convex ( $n p<0$ for this case).

$A$ and $A^{*}$ are respectively locations of the home country and the foreign country at a particular time. Then

$$
\left(f^{\prime}-x\right) \dot{k}-k \dot{x}<\left(f^{* \prime}-x^{*}\right) k^{*}-k^{*} x^{*}<0
$$

holds from Fig. (A-3) and from $(1-\beta c / c)<\beta^{*} d c_{-}$the sgn of ex becomes indeterminate from $(A-2)$ for the g-type adjustment cost.

\section{Appendix III}

\section{Figure A-3}


In this appendix, we analyze the h-type case.

\section{A. Net Cash Flow Maximization by Firm}

The value of firm $\widetilde{V}\left(k_{0}, 0\right)$ corresponding to (3) is written as

$$
\tilde{V}\left(k_{0} ; 0\right)=\max _{k} \int_{0}^{\infty}[f(k)-i(1+h(i / k))-w](0, \quad) d \text {. }
$$

The corresponding current value Hamiltonian is expressed as

$$
\tilde{H}(k, i, q)=f(k)-i(1+h(i / k))-w+q(i-(n+) k) .
$$

The first order conditions for maximization are

$$
\tilde{H}_{i}=-\left(1+h+h^{\prime} \cdot x\right)+q=0
$$

and

$$
\dot{q}=-\tilde{H}_{k}+q(r-n)=f^{\prime}-h^{\prime} \cdot x^{2}+q(+r) .
$$

The gdp is expressed as

$$
g d p=f(k)=c+i(1+h(x))+e x .
$$

The time rate of change of assets, $a$ is

$$
\dot{a}=\mathrm{s}-\mathrm{i}(1+h(\mathrm{x})) \text {. }
$$

The world's average consumption $\mathrm{c}$ is

$$
\bar{c}=f(k)+{ }^{*} f\left(k^{*}\right)-i\left(1+h(x)-{ }^{*}{ }^{*}\left(1+h\left(x^{*}\right)\right) .\right.
$$

\section{B. Utility Maximization by Consumers}

The consumer maximizes $U$ (c) defined by ( 8 ) subject to the flow budget constraint

$$
\dot{a}=f(k)-c-i(1+h(x))+(r-n) a .
$$




$$
\tilde{H}_{c}=u^{\prime}-p=0,
$$

(12) and (13).

(14), (15) and (16) also hold for the h-type case. Here

$$
F(k(t), t)=\int_{t}^{\infty}(f(k)-i(1+h(x)))(t,) d
$$

is the sum of firm value $V(k(t), t)$ and human capital $H(t)$.

\section{Uniqueness of the Stationary State of the World Economy}

This also holds for the h-type case with

$$
\begin{aligned}
& x_{\infty}=+n \quad(\text { with } \dot{k}=0) \text { and } \\
& f^{\prime}\left(k_{\infty}\right)-\left(1+h\left(x_{\infty}\right)\right) x_{\infty}=q_{\infty}(-n)
\end{aligned}
$$

where $q_{\infty}=1+h\left(x_{\infty}\right)+h^{\prime}\left(x_{\infty}\right) \cdot x_{\infty}$.

From $r_{\infty}=\theta,(1)^{\prime},(2)^{\prime},(5)^{\prime}$ and (6)', we obtain Fig. 1 and hegse $q=q(k)$, with $\mathrm{q}^{\prime}(\mathrm{k})<0$ follows. The same is true for the foreign country. Fence $E$ is again a local saddle point. Then the phase diagram obtained fo the system of two differential equations $\dot{k}=x(k) \cdot k-(n+\delta) k$ and $\dot{k}^{*}=x\left(k^{*}\right) \cdot k^{*}-(n+\delta) k^{*}$ is drawn as in Fig. 2. Again $E_{k}$ is a local stable node.

\section{Controlled Economy}

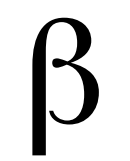

From the maximization of the controlled economy, i.e., the average world utility over time subject to (2)', its foreign counterpart, and (7)', we obtain the following Hamiltonian

$$
\begin{aligned}
\tilde{H} & \left.=u(c)+{ }^{*} u\left(c^{*}\right)+Q(i-(n+) k)+{ }^{*} Q^{*}\left(i-(n+) k^{*}\right)\right) \\
& +p\left(f(k)+{ }^{*} f\left(k^{*}\right)-i(1+h(i / k))-{ }^{*} i^{*}\left(1+h\left(i^{*} / k^{*}\right)\right)\right)
\end{aligned}
$$




$$
\begin{aligned}
& Q^{*}=p\left(1+h^{*}+h^{* 1} x^{*}\right) \\
& Q=(+) Q-p\left(f^{\prime}+h^{\prime} x^{2}\right) \\
& Q^{*}=(+) Q^{*}-p\left(f^{* \prime}+h^{*} x^{* 2}\right) .
\end{aligned}
$$

The equivalence between the decentralized economy and the controlled economy can be shown by a similar method to that used in the g-type case. Here for the h-type case, the system of differential equations consisting of (2)', its foreign counterpart, and (22)' and (23) ' constitute autonomous equations.

As in the g-type case, the function W,

$$
W\left(k_{0}, k_{0}^{*}\right)=\max _{k, k^{*}} \int_{0}^{\infty}\left\{u(c)+{ }^{*} u\left(c^{*}\right)\right\} e^{-(-n) t} d t
$$

is concave in $\left(\mathrm{k}_{0}, \mathrm{k}_{0}^{*}\right)$ and hence $\mathrm{Q}=\mathrm{Q}\left(\mathrm{k}, \mathrm{K}^{*}\right)$ and $\mathrm{Q}^{*}=\mathrm{Q}^{*}\left(\mathrm{k}, \mathrm{k}^{*}\right)$ with $\mathrm{Q}_{\mathrm{k}}<0$ and $Q_{k^{*}}^{*}<0$ follow. Then from (7)', (18), (19), (20)' and (21)', we obtain the dependency of $x$ and $x^{*}$ on $k$ and $k^{*}$. Again we obtain the system of two differential equations

$$
\begin{aligned}
& \dot{\mathrm{k}}=\mathrm{x} \cdot \mathrm{k}-(\mathrm{n}+) \mathrm{k} \\
& \dot{\mathrm{k}}^{*}=\mathrm{x}^{*} \cdot \mathrm{k}^{*}-(\mathrm{n}+) \mathrm{k}^{*}
\end{aligned}
$$

with $x=x\left(k, k^{*}\right)$ and $x^{*}=x^{*}\left(k, k^{*}\right)$. Boundedness of the opt mal path can be

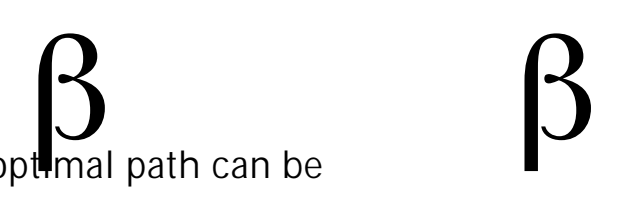
proven by a similar method to that used in the g-type case. For the h-type case, given $i_{2} k$ and $k^{*}$ with $k=k^{*}$ initially, the world's average consumption $c=\beta c+b^{*} c^{*}$ has to be maximized under the optimal path of $c_{-}$if the consumption efficiency is to hold. That is, from (7)'

$$
\begin{aligned}
& \bar{c}=f(k)+{ }^{*} f\left(k^{*}\right)-\bar{i}-i h(i / k)-{ }^{*} h\left(i^{*} / k^{*}\right) \\
& \text { - \&11, * * *1, * : :L1:11, * * *1:*1,*1 }
\end{aligned}
$$




\section{E. Trade Patterns and Asset-Debt Positions}

The dependency of $x$ and $r$ respectively on $q$ and $k$ is obtained from (2), (5)' and (6) ' by a similar method. Then (2)' and (6) ' with $i=x k, x=x(q)$ and $r=r(k)$ constitute the system of two dimensional autonomous differential equations. Since $r_{\infty}>x_{\infty}-\delta$ holds for the h-type case, we generalize this and assume

$$
\text { A. } 1 \quad r>x-\delta
$$

holds always. Then we obtain Fig. 5 and hence $q=q(k)$ with $q^{\prime}(k)<0$ and $q^{*}=q\left(k^{*}\right)$ with $q^{\prime}\left(k^{*}\right)<0$. Then from $x=x[q(k)]$, we obtain $d(k / k) / d k<0$ (Fig. 6). Then we see that $k_{0}>k_{0}^{*}$ implies $k>k^{*}$ al ways with $k_{\infty}=k_{\infty}^{*}$.

Since $f^{\prime}\left(k_{\infty}\right)-\left(1+h\left(x_{\infty}\right)\right) x_{\infty}=q_{\infty}(\theta-n)$ holds where $q_{\infty}=1+h\left(x_{\infty}\right)+h^{\prime}\left(x_{\infty}\right) \cdot x_{\infty}$ $f^{\prime}\left(k_{\infty}\right)>\left(1+h\left(x_{\infty}\right)\right) x_{\infty}$ follows. This is slightly generalized so that

$$
\text { A. } 2 \quad f^{\prime}(k)>(1+h(x)) \cdot x
$$

holds always. Since $n p=f(k)-i(1+h)$ and $i=x \cdot k$ hold,

$$
\dot{n i p}=\left(f^{\prime}(k)-(1+h) x\right) \dot{k}-\left(k+i \cdot h^{\prime}\right) \dot{x}
$$

follows. From $x=x(q(k))$ with $q^{\prime}(k)<0$, it follows that

$$
\dot{x}<0 \Leftrightarrow \dot{k}>0 \Leftrightarrow \dot{n p}>0 \quad \text { from A. } 2 \text {. }
$$

We fur ther assume

$$
\text { A. } 3 \ddot{n} \mathrm{p}<0 \text { if } \dot{k}>0 \text {. }
$$

Then

$$
f^{\prime} \cdot \dot{k}-i(1+h)-i h^{\prime} \dot{x}<f^{* \prime} k^{*}-i^{*}\left(1+h^{*}\right)-i^{*} h^{* 1} \dot{x}^{*}
$$

follows. From this Theorem 2 is obtained. (See Appendix II.) 